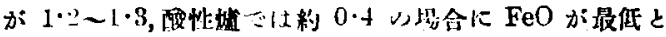
なる.

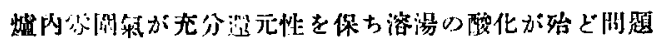

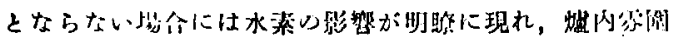

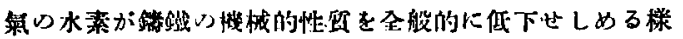
である. 似つて装入原料等からの水素の纹入を充分防上 せを代ならない。

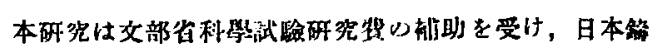

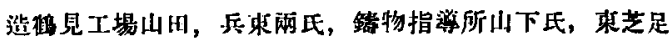

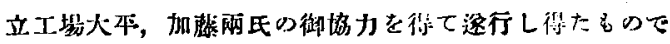

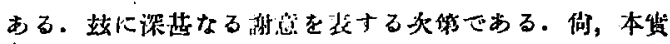

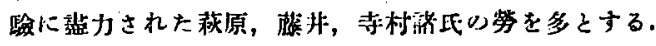

(明机 24 年 1 月器得)

\title{
大型特殊鋼材の㳄化燒鈍への等溫變態の應用 (II)
}

(昭和 23 年 4 月本合声演大會蓝㴼)

\author{
堀川 $川$ 男** \\ FULL ANNEALING OF LOW ALLOY STEEL THICK FORGINGS \\ BY A ISOTHERMAL TRASFORMATION

\section{Kazuo Horikaua}

Synopsis :

In this second report, experiments carried out on thick forgings were given. The forn, of the forgings was the cylinder, and dimensions were outer dia. 660, inner dia. 480 and length $4500 \mathrm{~mm}$.

The isothermal annealing operation consists in (1) heating the steel to a temperature just above its Ac range (2) cooling in air from $r$ state to the predetermined subcritical point (3) charging the steel into the furnace kept at the predetermined temperature and keeping the temperature constantly for a given time (4) cooling from that temperature to the atmospheric temperature in air.

The producer gas fired furnace was used.

The results obtained were summarized as follows ;

(1) The isothermal annealing operation of low alloy stsel thick forgings is quite easy.

(2) The time required for this annealing process is $1 / 2$ or less of the ordinary process.

(3) The annealed structure is satiefactorily and uniformly softened.

(4) The isothermal annealing develops the machinability of steel on account of its low hardness.

(5) This new annealing method has no bad influence upon the heat treating operation after annealing and mechanical properties after hardening and tenıpering.

\section{1繶}

\section{言}

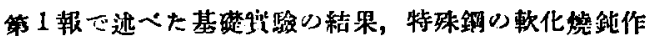

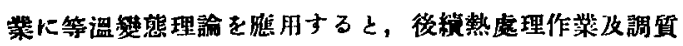

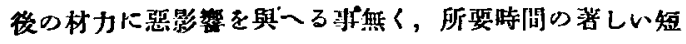

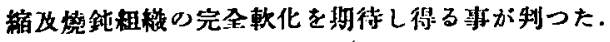

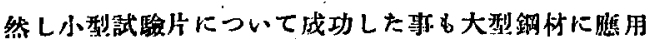
した場合に失败する㱒は璒々經驗するところであるか

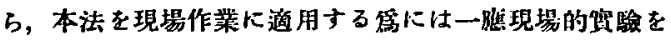

施行して確証する必要がある。

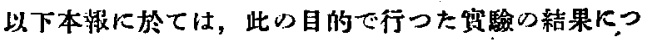
いて迅へる。

\section{II 霓 驗 方 法}

\section{（1）供 試材}

除種としては，比校的軟化され集い $\mathbf{A}$ を選んだ。 


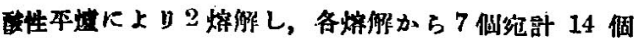

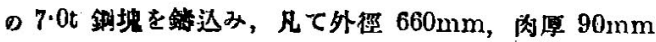

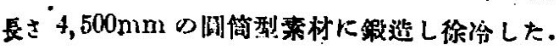

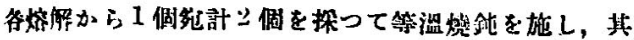

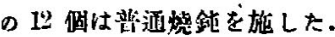

(e) 伎用 t

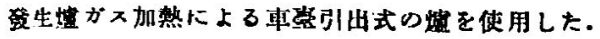

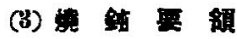

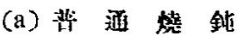

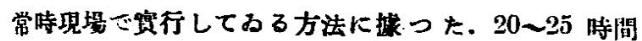
で利 $400^{\circ} \mathrm{C}$ から $700^{\circ} \mathrm{C}$ に男第し; 颜温度に 15 時間保 持後がス这りを止めて蛏冷に移り，40〜60時間にて $300^{\circ} \mathrm{C}$ 荙降げ，䗷加ら取出して等冾子る。

(b) 等 温 烧 鈍

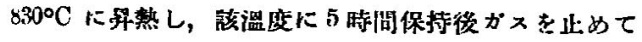

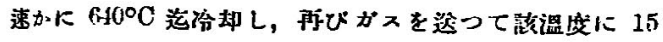
時間保持後蜼加ら取出して空冾する。

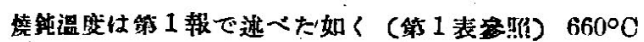

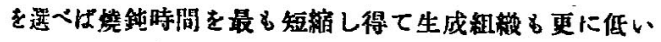
のだあるが，現望作業に於ては驼识其他不测の原因に

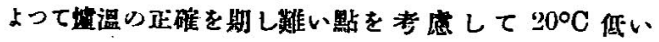

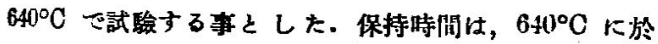

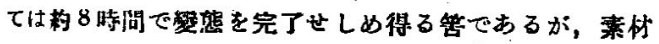

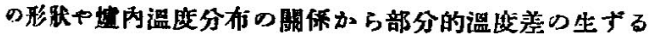
事を考虑して 2 倍に近い15 時間で行ふ事とした。

(4)西 唯

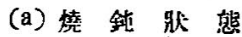

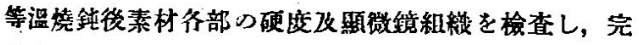

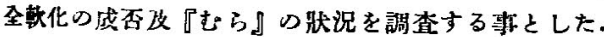

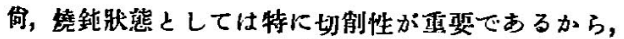

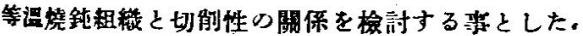

(b) 調 犋 爿 暜

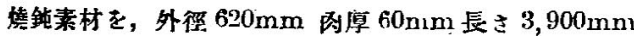

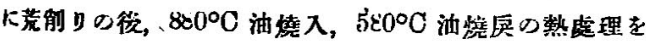
行って，橫方向に試驗片を採取し，烧鋪方法の相造が調

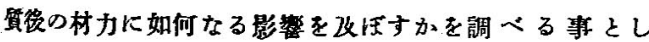
F.

\section{III 茟驗結果並に考察}

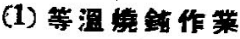

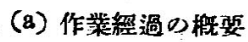

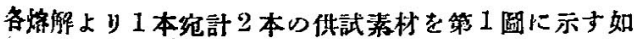
く並一，約 6 時間で $830^{\circ} \mathrm{C}$ 穴昇溫せしめ，該溫度に5 時間保持したが，操作上別段困難はなかつた。次にガス

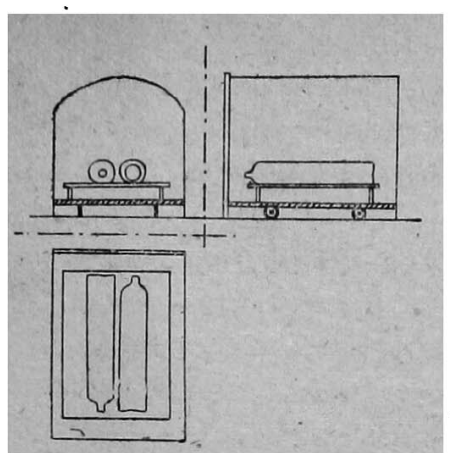

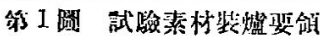

を止め，韭を 1.5 m 揚げて車缷を $1 \cdot 0 \mathrm{~m}$ 可出し, ガ ス交擬敨を中心に してダンパーを全 閉亡し，出柬る文 け速かに湓却世し めたのであるが, $830^{\circ} \mathrm{C}$ 加 $640^{\circ} \mathrm{C}$ 一心降溫狀㫛は, 稳入した $\mathrm{Pt}$ -

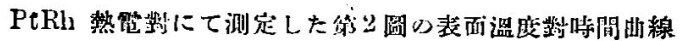

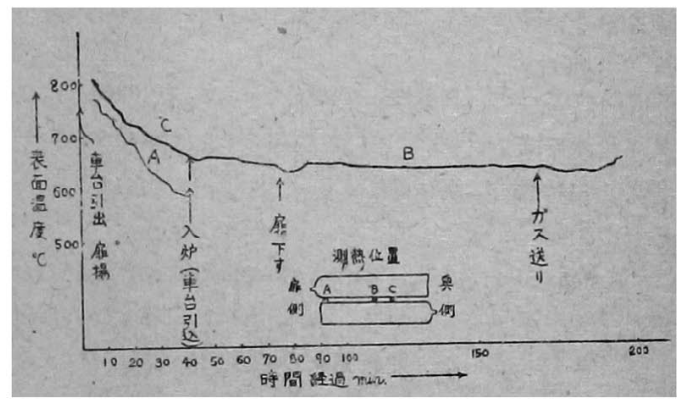

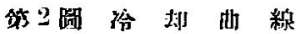

に示す如くであつた。即，所媭時問は䄪 1 時間であつ

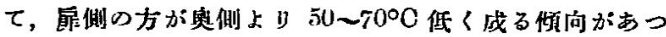
た，從つて，各部を均一に冷却せしむる跒には，此較的

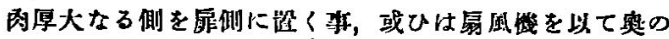
涫却を促進する必要がある。

素㭙の中央部が $660^{\circ} \mathrm{O}$ ，附近渠椧却した時を見諳つ て，阿び車焦を引込めて屝を䦌し；夷いで徐々にがスを 运つて $640^{\circ} \mathrm{O}$ に保持したのだある。此の間 $\pm 10^{\circ} \mathrm{O} の$

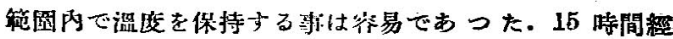
過後 $640^{\circ} \mathrm{C}$ から直に空泠したが, 別に異狀は認めなか つた.

(b) 今後的方案

今包の贯駰から，現場的に施行するには次の如く方案 を改良した方が良いと思は机る８ $830^{\circ} \mathrm{C}$ からの洽却は， 素材を娬外に取出して，艾持管上にて些汾せしめ，表面

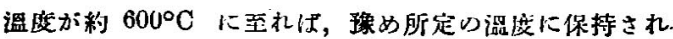
た惯の內に装入する。

份，若し来情が許せば，蚍造後徐冷する事然く直ちに

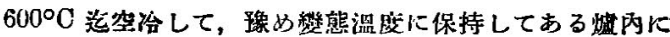
装入する．斯る方法に依れば車に洔間，燃料の節約が期 待出來る篦であり，白點及割れ防止の見地からも理想的 である考へる。 
(c) 所 恐 時 成

A

$\mathbf{B}$

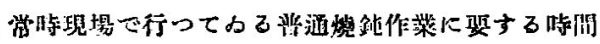

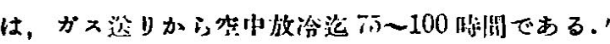

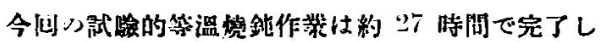
$\tau わ る$.

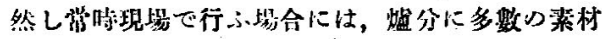

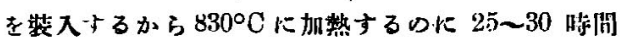

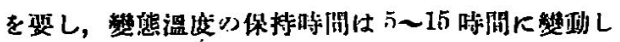

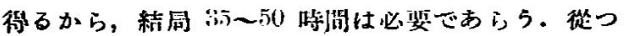
て䄪 $1 /$ に短縓し得るわけである。

更に若し素材を鹤造後计に $660^{\circ} \mathrm{C}$ 前後D溫度に保持し

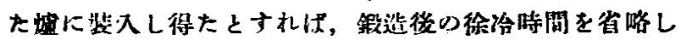

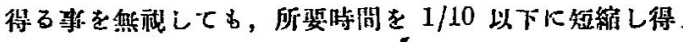
る管である。

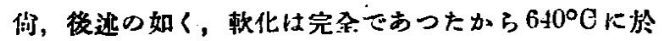

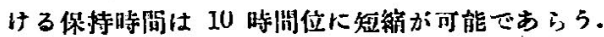

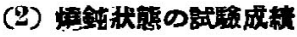

\section{(a) 硬证}

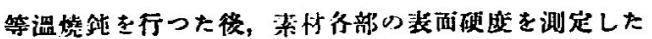

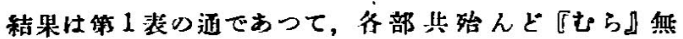
第 1 表 烧㖉素材の硬度分布

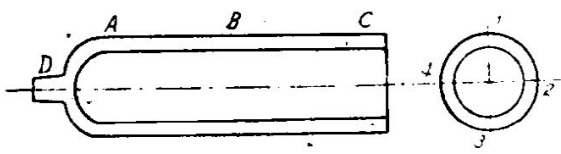

\begin{tabular}{|c|c|c|c|c|c|c|}
\hline 素材番號 & & A & B & C & $\mathrm{D}$ & 考 \\
\hline $614937 / 7$ & $\begin{array}{l}1 \\
2 \\
3 \\
4\end{array}$ & $\begin{array}{l}18.5 \\
197 \\
193 \\
18^{23} \\
.\end{array}$ & $\begin{array}{l}180 \\
195 \\
192 \\
197\end{array}$ & $\begin{array}{l}182 \\
187 \\
180 \\
176\end{array}$ & $\begin{array}{l}187 \\
199 \\
205 \\
144\end{array}$ & 等盢燥針材 \\
\hline $616: 293 / 7$ & $\begin{array}{l}1 \\
2 \\
3 \\
4\end{array}$ & $\begin{array}{l}164 \\
176 \\
180 \\
172\end{array}$ & $\begin{array}{l}166 \\
172 \\
176 \\
160\end{array}$ & $\begin{array}{l}166 \\
187 \\
168 \\
170\end{array}$ & $\begin{array}{l}184 \\
181 \\
176 \\
174\end{array}$ & \\
\hline $61629^{2} / 7$ & $\begin{array}{l}1 \\
2 \\
3 \\
4\end{array}$ & $\begin{array}{l}197 \\
204 \\
210 \\
198\end{array}$ & $\begin{array}{l}198 \\
211 \\
215 \\
199\end{array}$ & $\begin{array}{l}191 \\
202 \\
207 \\
195\end{array}$ & $\begin{array}{l}175 \\
170 \\
178 \\
179\end{array}$ & 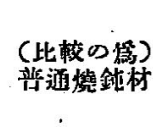 \\
\hline
\end{tabular}

數字はプッネル硬度

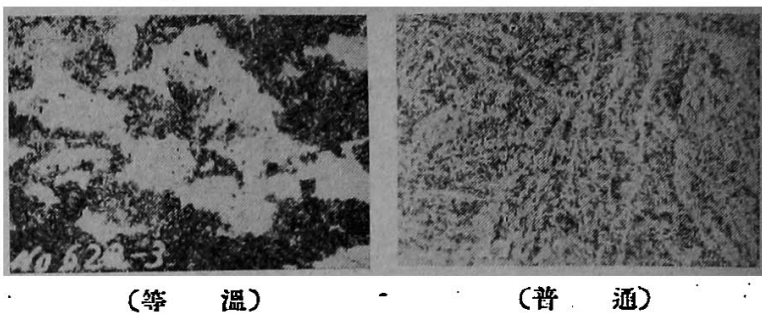

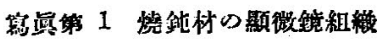
$\times 200^{-} .2 \%$ Nital etch

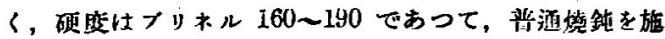
行したるの攼く，完全に軟化してるた。

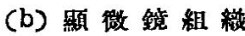

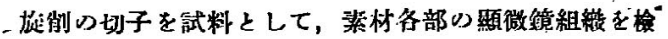

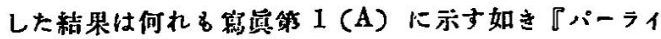
トゥ十『フェライト』の混合租轹を示し，各部間に殆んど

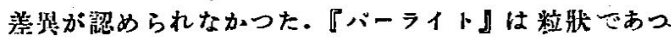

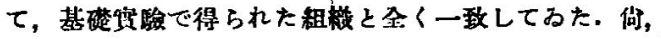

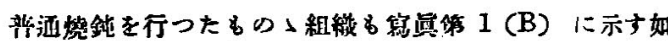

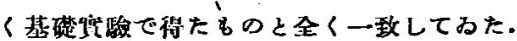

以上 (a) 及 (b) の政果から，小型試驗片に上り成功

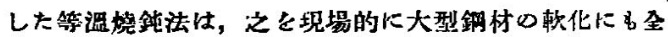

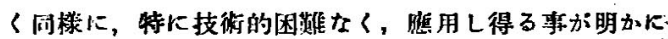
なつた。

(c) 切㓩 性:

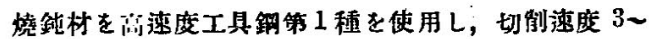
$5 \mathrm{~m} / \mathrm{min}$, 切込 $20 \sim 40 \mathrm{~mm}$ 运 り $1.6 \sim 2.5 \mathrm{~mm} / \mathrm{rev}$, の

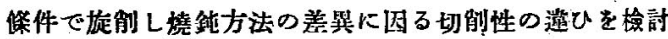

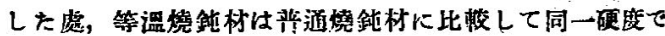

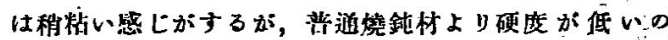

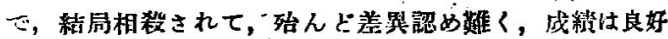
である。

(d) 機 棫的性 質

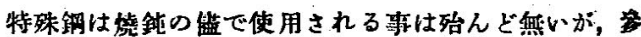

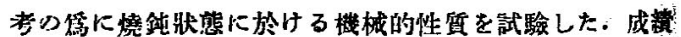
は第 2 表の通りであつて，橈針方法の相違に园る差は殆 んど無いが，特に比較すれば等溫埶鈍を行つそものい方

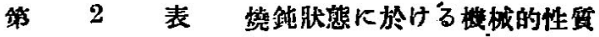

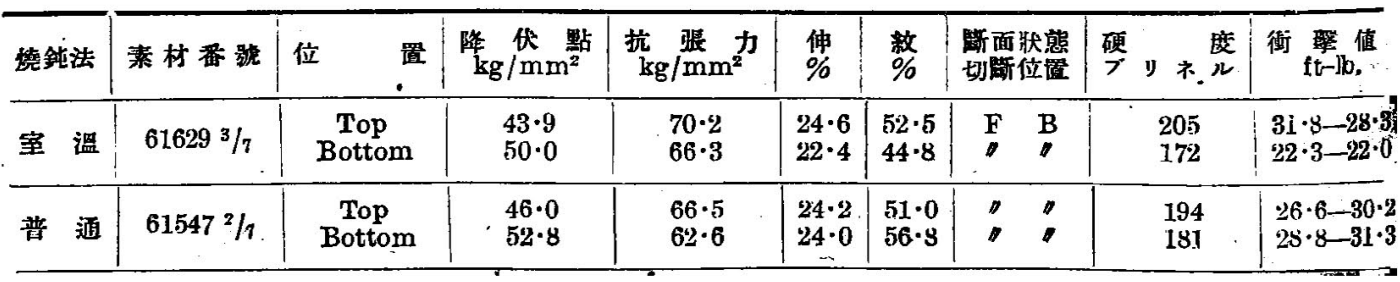


揢解番撢 61499

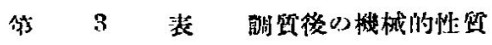

$\begin{array}{ccccccccc}\mathrm{C} & \mathrm{Si} & \mathrm{Mn} & \mathrm{P} & \mathrm{S} & \mathrm{Ni} & \mathrm{Cr} & \mathrm{C} 1 & \mathrm{~N} \omega \\ 0.31 & 0.26 & 0.85 & 0.024 & 0.033 & 1.18 & 1.12 & 0.08 & 0.44\end{array}$

\begin{tabular}{|c|c|c|c|c|c|c|c|c|c|c|c|c|}
\hline 兒 & 釓 & 法 & 来标 & 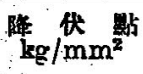 & 莎 $\mathrm{kg} / \mathrm{mnn}^{2}$ 力 & 他 & $\begin{array}{l}\text { 舷 } \\
\%\end{array}$ & 莃 & 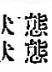 & $\frac{\text { 硬 }}{7^{\prime}}$ & リネ度 & 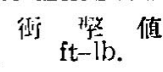 \\
\hline 亚 & . & 通 & $\begin{array}{l}i / 7 \\
2 / 7 \\
3 / 7 \\
4 / 7 \\
5 / 7 \\
6 / 7\end{array}$ & $\begin{array}{r}110 \cdot 0 \\
103 \cdot 0 \\
103 \cdot 0 \\
117 \cdot 0 \\
98 \cdot 0 \\
118 \cdot 0\end{array}$ & $\begin{array}{l}120 \cdot 5 \\
1: 6 \cdot 8 \\
112 \cdot 0 \\
127 \cdot 7 \\
108 \cdot 0 \\
121 \cdot 0\end{array}$ & $\begin{array}{l}1+\cdot 4 \\
15 \cdot 0 \\
15 \cdot 5 \\
14 \cdot 4 \\
1 \% \cdot 4 \\
15 \cdot 5\end{array}$ & $\begin{array}{l}43 \cdot 7 \\
45 \cdot 4 \\
44 \cdot 3 \\
41 \cdot 6 \\
49 \cdot 0 \\
43 \cdot 7\end{array}$ & $\begin{array}{c}\mathrm{F} \\
\mathrm{Cup} \\
\mathrm{F} \\
\prime \prime\end{array}$ & $\begin{array}{l}\text { B } \\
" 1 \\
" 1 \\
" 1 \\
" 1\end{array}$ & $\begin{array}{l}\text { ! } \\
\text { ! }\end{array}$ & $\begin{array}{l}352 \\
3+1 \\
324 \\
377 \\
319 \\
352\end{array}$ & $\begin{array}{l}30 \cdot 0-3 \cdot \cdot 2 \\
82 \cdot 7-33 \cdot 5 \\
35 \cdot 0-34 \cdot 5 \\
64 \cdot 0-39 \cdot 0 \\
25 \cdot 5-37 \cdot 3 \\
30 \cdot 4-31 \cdot 7\end{array}$ \\
\hline 等 & & 温 & $7 / 7$ & $104 \cdot 0$ & $115 \cdot 5$ & $15 \cdot 0$ & $4 L \cdot 6$ & $"$ & $"$ & & 337 & $32 \cdot 0-30 \cdot 0$ \\
\hline
\end{tabular}

罃解番號 61629

$\begin{array}{ccccccccc}\mathrm{C} & \mathrm{Si} & \mathrm{Mn} & \mathrm{P} & \mathrm{S} & \mathrm{Ni} & \mathrm{Cr} & \mathrm{Cu} & \mathrm{Mu} \\ 0.30 & 0.16 & 0.73 & 0.036 & 0.027 & 0.78 & 0.98 & 11.4 .9 & 11.49\end{array}$

\begin{tabular}{|c|c|c|c|c|c|c|c|c|c|c|c|c|}
\hline 峌 & 鈍 & 法 & 泰材番 & 降、伏 點 & 执 $\underset{\mathrm{kg} / \mathrm{mm}^{3} \text {. }}{\text { 力 }}$ & $\begin{array}{l}\text { 仲 } \\
0\end{array}$ & $\begin{array}{l}\text { 絞 } \\
\%\end{array}$ & 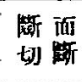 & 伙热 & 硬， & y*度 & 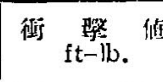 \\
\hline 萻 & & 通 & $\begin{array}{l}1 / 7 \\
2 / 7 \\
4 / 7 \\
5 / 7 \\
6 / 7 \\
7 / 7\end{array}$ & $\begin{array}{l}i 04 \cdot 0 \\
104 \cdot 0 \\
100 \cdot 0 \\
11 \% \cdot 5 \\
101 \cdot 5 \\
110 \cdot 0\end{array}$ & $\begin{array}{l}119 \cdot 8 \\
113 \cdot 0 \\
107 \cdot 8 \\
123 \cdot 0 \\
110 \cdot 0 \\
119 \cdot 0\end{array}$ & $\begin{array}{l}36 \cdot 8 \\
15 \cdot 8 \\
16 \cdot 0 \\
35 \cdot 0 \\
17 \cdot 8 \\
16 \cdot 9\end{array}$ & $\begin{array}{l}42 \cdot 1 \\
40 \cdot 5 \\
48 \cdot 0 \\
41 \cdot 6 \\
50 \cdot 0 \\
43 \cdot 2\end{array}$ & $\begin{array}{l}\mathrm{F} \\
" \prime \\
\prime \prime \\
" \prime \\
" \prime\end{array}$ & $\begin{array}{l}-\mathrm{B} \\
" 1 \\
\mathrm{~A} \\
\mathrm{~B} \\
" \prime \\
"\end{array}$ & $\vdots$ & $\begin{array}{l}341 \\
333 \\
311 \\
356 \\
320 \\
350\end{array}$ & $\begin{array}{l}31 \cdot 3-32 \cdot 0 \\
33 \cdot 5-32 \cdot 0 \\
32 \cdot 5-38 \cdot 3 \\
36 \cdot 0-28 \cdot 0 \\
37 \cdot 7-39 \cdot 5 \\
31 \cdot 5-31 \cdot 5\end{array}$ \\
\hline 繁 & & 泳 & $3 / 7$ & $103 \cdot 0$ & $113 \cdot 0$ & $16 \cdot 4$ & $43 \cdot 7$ & Cup & $\mathbf{A}$ & & $33 \mathrm{~L}$ & $24 \cdot 0-30 \cdot 5$ \\
\hline
\end{tabular}

が，抗張力ゆ制合に降伏點及街拏值が低目である。

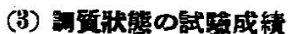

绖釷材を何れ外徑 $620 \mathrm{~mm}$, 肉厚 $60 \mathrm{~nm}$, 長さ

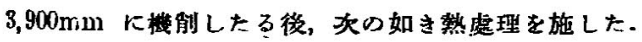
6〜7 時間にて $880^{\circ} \mathrm{C}$ に加㷫 $し$, 旅溫度に 25 時問保持

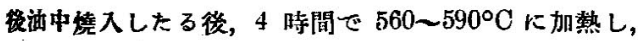

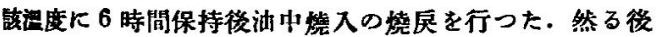

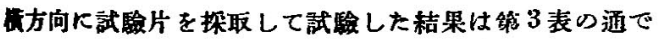

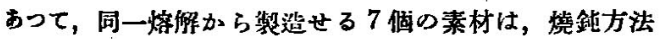

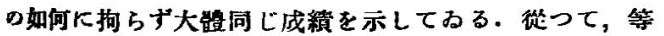

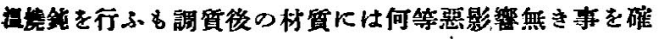
嫼し得た:

$$
\text { IV 總括 }
$$

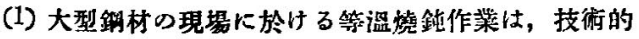
に特に困難を件ふ事なく理論通り鿓施し得た。

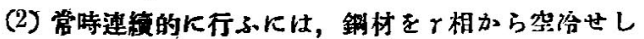

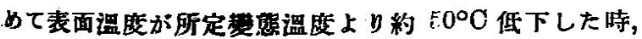

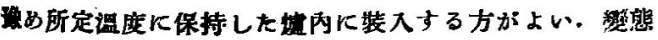
洞度に於りる保持時間は特に理論值以上に延長する必要 はない.

(3) 燒鈍所要時間を $1 / 2$ 以下に短縮し得る事が制つ
做，所努時閑は更に $1 / 10$ 以下に短縮し得る見迅があ 了。

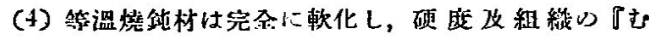
门』は䍢かつた。

(5)等溫燒的材は硬度低き第，切削性は良好である。

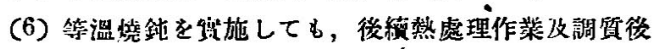

の材力に惡い影警を及改す护はない。

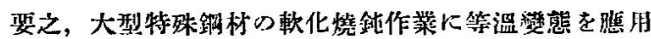

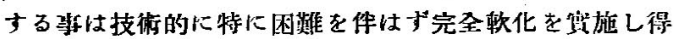

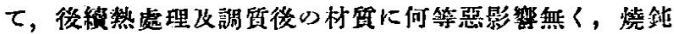

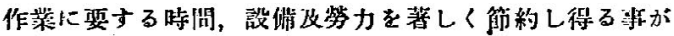
制つた.

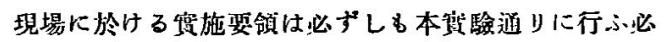

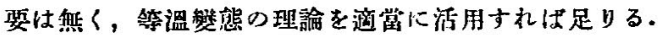

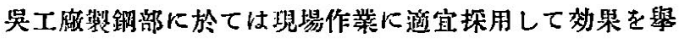
げてるた・

一本研究は中前和夫氏心御指導を受け，基礎察驗には荒 川基資氏のメ現場识驗には佐々木博氏の御嗳助老得て透

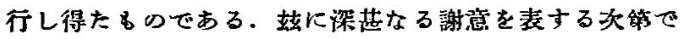
ある.

(沿和 23 年 11 月寄福) 